\title{
Investigation on vitamin D knowledge, attitude and practice of university students in Nanjing, China
}

\author{
Ming Zhou ${ }^{1, *}$, Weiwei Zhuang ${ }^{2}$, Yunyun Yuan ${ }^{3}$, Zhong $\mathrm{Li}^{1}$ and Yunqing Cai ${ }^{1}$ \\ 'Department of Nutrition and Food Hygiene, School of Public Health, Naniing Medical University, 101 Longmian \\ Road, Jiangning District, Nanjing 211166 , People's Republic of China: ${ }^{2}$ Center for Disease Prevention and Control \\ of Qixia District, Nanjing, People's Republic of China: ${ }^{3}$ Center for Health Service of Jiangqiao Community, \\ Shanghai, People's Republic of China
}

Submitted 7 January 2014: Final revision received 26 December 2014: Accepted 7 January 2015: First published online 23 February 2015

\begin{abstract}
Objective: To investigate university students' knowledge, attitudes and practice (KAP) regarding vitamin D.

Design: The students were requested to answer a questionnaire related to vitamin D and sun exposure. The consumption frequency of foods rich in vitamin D was assessed. Additionally, the intake of vitamin D-containing supplements was recorded. Setting: A medical university in Nanjing, China.

Subjects: Five hundred and fifteen medical students were included.

Results: The highest rate of correct responses for the quiz was $68.0 \%$, while the lowest was $9.6 \%$. Most students lacked sun exposure because they did not want to get tanned; $82.7 \%$ of students used some sun protection and sunscreen use was more popular in the female group. The consumption frequency of foods rich in vitamin D was low and $5.6 \%$ of the students used vitamin D supplements. The students' knowledge on vitamin D was derived mainly from the media and health professionals. Most of the students were interested to know more about vitamin D.

Conclusions: The present study suggested that medical students had little knowledge and unfavourable behaviours. They should get more health education through the media and health professionals. It is advisable to increase their consumption of foods rich in vitamin D.
\end{abstract}

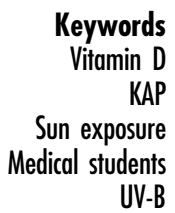

Vitamin D is an essential dietary micronutrient. Other than the traditionally recognized effects of vitamin $\mathrm{D}$ on $\mathrm{Ca}$ metabolism, numerous scientific studies also show that vitamin D deficiency may increase the risks for developing non-skeletal disorders such as CVD, obesity, high blood pressure, diabetes, autoimmune disease, depression and selected cancers $^{(1,2)}$. While vitamin D can be derived from dietary sources, sun exposure is essential for the synthesis of vitamin D: in man, UV-B radiation acting on the skin is the major source of vitamin $D^{(3,4)}$. Vitamin D deficiency is still at epidemic proportions worldwide ${ }^{(5)}$. In mainland China, there has been no systematic national survey to assess levels of vitamin D deficiency; however, findings from some surveys suggest that vitamin D deficiency is prevalent in young people ${ }^{(6-9)}$. Although studies worldwide have identified lack of sun exposure as the main cause of vitamin D deficiency ${ }^{(10)}$, there is limited awareness of the association between sun exposure and vitamin D synthesis in some populations ${ }^{(11-13)}$. The transition from adolescence to young adulthood is gaining recognition as an important period for health promotion and disease prevention $^{(14)}$. To the best of our knowledge, no study about knowledge, attitude and practice (KAP) regarding vitamin $\mathrm{D}$ among university students has been conducted before in China. Moreover, the problem of vitamin D deficiency among university students in China has not been given sufficient attention. Therefore the present study explored the relationship between vitamin D and sun exposure attitude, knowledge and practice of university students.

\section{Methods}

\section{Study participants}

The participants were drawn by random cluster sampling from students attending elective courses at Nanjing Medical University. Our university provides a wide variety of elective courses about medicine, music, arts, linguistics and management science. To avoid the influence of 
knowledge acquired during their elective course, the present investigation was carried out with students at beginning of the course.

\section{Procedure of investigation}

A KAP questionnaire was developed and pre-tested to facilitate a semi-structured interview. Most of the questions were closed-ended and the responses of participants were directly transcribed during the interview. First, participants completed a quiz. They were asked about six topics related to vitamin $\mathrm{D}$ and determined which was the best answer for questions. Each topic had three choices: true, false and 'don't know'. Knowledge scores were calculated according to the principle that every correct answer was equivalent to 1 point, and the maximum total score was 6 points. Then, some questions investigated the students' attitudes and practice (behaviours) regarding vitamin D and sun exposure (Table 1). Finally, the students' consumption of some foods rich in vitamin $\mathrm{D}$ was assessed. The three most common food sources of vitamin D in China were selected. All consumption frequencies were standardized into frequency per month. Respondents were also inquired about their intake of vitamin D-containing supplements. All data were gathered from standard questionnaires in Chinese language administered by trained staff.

\section{Statistical analysis}

The statistical software package IBM SPSS Statistics 19 was used for statistical analysis. All experimental data are presented as means and standard deviation or percentage. Continuous and categorical data were examined by Student's $t$ test and the $\chi^{2}$ test, respectively. A $P$ value of less than 0.05 was considered statistically significant.

\section{Results}

\section{Characteristics of participants}

In total, 550 students were invited to participate; 515 valid questionnaires were returned (93.6\% participation rate), with notably more females $(73 \cdot 2 \%)$ than males $(26 \cdot 8 \%)$.

\section{Knowledge of vitamin $D$}

Our data showed that the rate of correct responses for four topics was below $50 \%$. Two-thirds of students knew the source of vitamin D; however, only $10 \%$ of students could give a correct answer about the peak of bone mass (Table 2 ). We also found that the average score was $2 \cdot 41$ (SD 1.51) points for male students and 2.56 (SD 1.38) points for female students, but there was no gender difference in this knowledge (Student's $t$ test: $P=0 \cdot 31$ ).

\section{Status of sun exposure}

Regarding length of daily sun exposure, thirty-five (6.8\%) students stated that they spent less than $15 \mathrm{~min} / \mathrm{d}$ in the sun, $164(31.8 \%)$ reported spending $15-30 \mathrm{~min} / \mathrm{d}, 141$ (27.4\%) noted exposure for 30-45 min/d and $175(34.0 \%)$ stayed out in the sun for $>45 \mathrm{~min} / \mathrm{d}$. Furthermore, $67.5 \%$ thought that their sun exposure was enough, but $32.5 \%$

Table 1 The questions on attitude and practice regarding vitamin $\mathrm{D}$ and sun exposure administered to medical students ( $n 515)$, Nanjing, China

\begin{tabular}{|c|c|}
\hline Question & Responses \\
\hline 1. The average length of daily sun exposure in summer and autumn & $\begin{array}{l}<15 \min \\
15-30 \min \\
30-45 \min \\
>45 \min \end{array}$ \\
\hline 2. Are you getting enough sun exposure? & $\begin{array}{l}\text { Yes } \\
\text { No }\end{array}$ \\
\hline 3. Your primary reason for avoiding the sun & $\begin{array}{l}\text { Avoiding dark skin (tanning) } \\
\text { Accelerating ageing } \\
\text { Skin cancer } \\
\text { Others }\end{array}$ \\
\hline 4. Use of sun protection in summer and autumn & $\begin{array}{l}\text { Always } \\
\text { Often } \\
\text { Sometimes } \\
\text { Rarely } \\
\text { Never }\end{array}$ \\
\hline 5. Your primary sun protection & $\begin{array}{l}\text { Sunscreen } \\
\text { Umbrellas } \\
\text { Hats } \\
\text { Others }\end{array}$ \\
\hline 6. Where have you heard about vitamin D? & $\begin{array}{l}\text { Health professionals (doctors, teachers, dietitians) } \\
\text { Media (Internet, television, radio, newspapers) } \\
\text { Classmates and friends } \\
\text { Others }\end{array}$ \\
\hline 7. Are you interested to know more about vitamin D? & $\begin{array}{l}\text { Yes } \\
\text { No } \\
\text { Indifferent }\end{array}$ \\
\hline
\end{tabular}


Table 2 The responses to topics about vitamin D among medical students ( $n$ 515), Nanjing, China

\begin{tabular}{|c|c|c|c|}
\hline Topic about vitamin D & True/false & Correct response & $\begin{array}{l}\text { Rate of correct } \\
\text { responses (\%) }\end{array}$ \\
\hline 1. Vitamin $\mathrm{D}$ belongs to the water-soluble vitamins & $\mathrm{F}$ & Vitamin $\mathrm{D}$ is a fat-soluble vitamin & 33.8 \\
\hline $\begin{array}{l}\text { 2. Vitamin } D \text { can prevent diabetes, cancer and other } \\
\text { chronic diseases }\end{array}$ & $\mathrm{T}$ & $\mathrm{N} / \mathrm{A}$ & 43.6 \\
\hline 3. Excessive intake of vitamin D can cause poisoning & $\mathrm{T}$ & $\mathrm{N} / \mathrm{A}$ & $57 \cdot 3$ \\
\hline $\begin{array}{l}\text { 4. Bone mass peak generally appears around the age } \\
\text { of } 20\end{array}$ & $\mathrm{~F}$ & $\begin{array}{l}\text { Bone mass peak generally appears at about } \\
\qquad 30 \text { years of age }\end{array}$ & $9 \cdot 6$ \\
\hline $\begin{array}{l}\text { 5. The human body can get vitamin } D \text { through sun } \\
\text { exposure }\end{array}$ & $\mathrm{T}$ & $\mathrm{N} / \mathrm{A}$ & $68 \cdot 0$ \\
\hline 6. Meat is a kind of vitamin D-rich food & $\mathrm{T}$ & $\mathrm{N} / \mathrm{A}$ & 43.0 \\
\hline
\end{tabular}

$\mathrm{N} / \mathrm{A}$, not applicable.

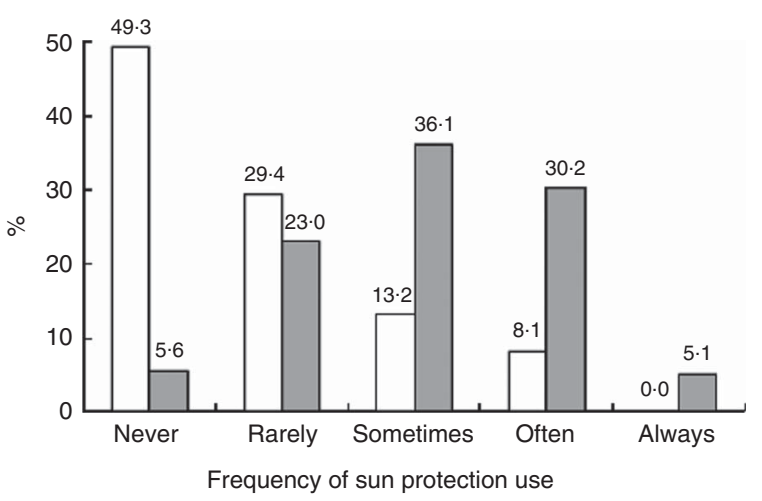

Fig. 1 Proportion using sun protection measures during the summer and autumn according to frequency and gender $(\square$, males; $\square$, females) among medical students (n515), Nanjing, China

gave a negative response. Subsequently, the reasons for avoiding the sun were investigated. Among those who indicated inadequate sun exposure, the three most frequent reasons among forty-four male students were avoiding dark skin (43.2\%), no desire to go out (18.2\%) and skin cancer (13.6\%). However, the three most frequent reasons for 124 female students were avoiding dark skin (75.0\%), skin cancer (16.1\%) and accelerating ageing (12.1\%).

\section{Use of sun protection}

Overall, $426(82.7 \%)$ of the participants used some sun protection. Nearly half of male students never used sun protection, with the proportion of males in increasing frequency of sun protection use (categories of never/ rarely/sometimes/often/never) decreasing gradually. Conversely, only $5.6 \%$ of female students never used protective measures and $30.2 \%$ of female students often had the aid of sun protection (Fig. 1). Thus, there were significant differences between males and females $\left(\chi^{2}\right.$ test: $\left.P=0 \cdot 000\right)$. The most common types of sun protection used by the male group ( $n 70$ ) were hats ( $>50 \%$ of male students wore them), sunscreen (33\%) and umbrellas (20\%). In contrast, $75 \%$ of the female group ( $n$ 356) used sunscreen as a popular protective measure against the sun, followed by umbrellas (72\%) and hats (42\%).

\section{Sources of information about vitamin $D$}

The majority of the participants $(59.5 \%)$ indicated that they had obtained information about vitamin $\mathrm{D}$ from the media (Internet, television, radio, newspapers), while $43.3 \%$ got their information through health professionals (doctors, teachers, dietitians) and $25.0 \%$ stated that their information was given by classmates and friends. Only $8.8 \%$ said that they had acquired information from their parents.

\section{Attitude towards vitamin D}

When students were asked whether they were interested to know more about vitamin $\mathrm{D}$, most of them gave an affirmative response; only $3.0 \%$ had no desire to learn about vitamin D. The thirst for knowledge was stronger in the female participants than the males (88.3\%v. $78.5 \%)$. More male students took an indifferent attitude compared with the female students $(18.5 \% v .8 .7 \%)$. There was a significant gender difference in attitude toward vitamin D $\left(\chi^{2}\right.$ test: $\left.P=0.003\right)$.

\section{Consumption of foods rich in vitamin $D$ and supplement use}

The results showed that almost all of the students often consumed eggs, while only half of them consumed marine fish. More importantly, students ate eggs every day, but they ate marine fish and liver only once or twice per month (Table 3). Additionally, only $5.6 \%$ of students used cod-liver oil, the most common vitamin D supplement.

\section{Discussion}

University students are in a critical period for the development of lifestyles which are very important for their future health. University students tend to engage in problematic eating behaviours, including unhealthy dieting, high intake of fast foods, low intake of fruits and vegetables, and minimal consumption of dairy products ${ }^{(15)}$. Healthy dietary habits among students of health sciences are vital, as they themselves will become health-care professionals, and students who ignore adopting a healthy 
Table 3 Consumption of selected foods rich in vitamin D among medical students ( $n$ 515), Nanjing, China

\begin{tabular}{lcc}
\hline Food & $\begin{array}{c}\text { Food consumption } \\
\text { rate (\%) }\end{array}$ & $\begin{array}{c}\text { Frequency } \\
\text { per month }\end{array}$ \\
\hline Marine fish & 50.5 & 1.0 \\
Liver & 77.1 & 2.0 \\
Eggs & 99.6 & 30.0 \\
\hline
\end{tabular}

lifestyle are more likely to fail to convince or promote health for their patients or clients ${ }^{(16)}$.

Vitamin D, the sunshine vitamin, is an essential dietary micronutrient. Vitamin D status is traditionally measured through assays of 25-hydroxyvitamin D, the major circulating form of vitamin $\mathrm{D}^{(17)}$. Although we did not measure 25-hydroxyvitamin D levels, some studies have shown that questionnaires can be used to predict vitamin deficiency $^{(18,19)}$.

Our findings revealed clear evidence of insufficient knowledge in this population. In particular, a high proportion of participants did not know the correct time for bone mass peak. Peak bone mass occurs at about 30 years of age ${ }^{(20)}$ and models indicate that interventions to increase peak bone mass could effectively delay the development of osteoporosis ${ }^{(21)}$. Therefore, if students know about this as early as possible, improved status of vitamin $\mathrm{D}$ will help them achieve higher peak bone mass.

Although $68 \%$ of the participants agreed that the human body can get vitamin $\mathrm{D}$ through sun exposure, only onethird of them stayed outside for more than $45 \mathrm{~min} / \mathrm{d}$ during summer and autumn. This may reduce their vitamin D synthesis from sunshine. However, most students believed their sun exposure was enough. Regardless of gender, the main reason for preventing sun exposure was avoiding dark skin (tanning). The lack of sun exposure was further demonstrated in the use of sun protection, especially in female students. For years, many health campaigns have successfully promoted the use of sunscreen with a high SPF (sun protection factor) to prevent skin cancer. However, the use of sunscreen products prevents UV-B rays from being absorbed by the body and therefore vitamin D cannot be produced ${ }^{(22)}$. Moreover, sunscreens were the most popular form of sun protection. A study performed in Western Europe, Australia and the USA found that $86 \%$ of the responders declared they always took precautions against UV exposure ${ }^{(23)}$. Our study also showed that females reported higher sunscreen use than males. It also found that the media was the main source of information about vitamin D for almost $60 \%$ of participants, as in another study ${ }^{(24)}$. Most students did not get information from their parents and perhaps this was because parents were not informed.

Other than sunshine, some foods items are important sources of vitamin D. Vitamin D-fortified food products are rare in China, so only the three most common foods were selected. The results indicated that the consumption frequency of some foods rich in vitamin D was low. Based on eating habits of the Chinese, consumption frequency of eggs was higher than in Korean adolescents and could be very beneficial in individuals who are at risk of vitamin D deficiency $^{(25-27)}$.

Taken together, our findings indicate that medical students are not fully aware of the benefits of vitamin D and therefore more health education seems vital to improve their knowledge and behaviour. Fortunately, most students are interested to know more about vitamin D. This should be good news for health education. Our results also evidence the need for actively increasing time outdoors. In addition, the consumption of foods rich in vitamin D could be encouraged through media campaigns and the guidance of health professionals.

\section{Acknowledgements}

Financial support: This work was supported by the Jiangsu Provincial Natural Science Foundation of China (grant number BK2010540); the Natural Science Fund for Colleges and Universities in Jiangsu Province (grant number 13KJB330001); the Practice Innovation Training Program Projects for Jiangsu College Students (grant number 2012JSSPITP1059); and the Priority Academic Program Development of Jiangsu Higher Education Institutions (2011) from Jiangsu Provincial Department of Education. The funders had no role in the design, analysis or writing of this article. Conflict of interest: None. Authorship: M.Z. was responsible for the study design and conception, data collection, manuscript drafting and final editing. W.Z. and Y.Y. participated in the study design, data collection, analysis and interpretation, and writing. Z.L. and Y.C. participated in the study design and supervision, writing and final editing. All authors approved the final manuscript. Ethics of buman subject participation: The study was approved by the Research Ethics Committee of Nanjing Medical University. Written informed consent was obtained from all participants.

\section{References}

1. Wacker M \& Holick MF (2013) Vitamin D - effects on skeletal and extraskeletal health and the need for supplementation. Nutrients 5, 111-148.

2. Fleet JC, DeSmet M, Johnson R et al. (2012) Vitamin D and cancer: a review of molecular mechanisms. Biochem J441, 61-76.

3. Burgaz A, Akesson A, Oster A et al. (2007) Associations of diet, supplement use, and ultraviolet $\mathrm{B}$ radiation exposure with vitamin $\mathrm{D}$ status in Swedish women during winter. Am J Clin Nutr 86, 1399-1404.

4. Woo J, Lam CW, Leung J et al. (2008) Very high rates of vitamin D insufficiency in women of child-bearing age living in Beijing and Hong Kong. Br J Nutr 99, 1330-1334.

5. Hilger J, Friedel A, Herr R et al. (2014) A systematic review of vitamin D status in populations worldwide. BrJ Nutr 111, $23-45$. 
6. Zhang W, Stoecklin E \& Eggersdorfer M (2013) A glimpse of vitamin D status in Mainland China. Nutrition 29 953-957.

7. Foo LH, Zhang Q, Zhu K et al. (2009) Low vitamin D status has an adverse influence on bone mass, bone turnover, and muscle strength in Chinese adolescent girls. J Nutr 139, 1002-1007.

8. Arguelles LM, Langman CB, Ariza AJ et al. (2009) Heritability and environmental factors affecting vitamin D status in rural Chinese adolescent twins. J Clin Endocrinol Metab 94, 3273-3281.

9. Zhu Z, Zhan J, Shao J et al. (2012) High prevalence of vitamin $D$ deficiency among children aged 1 month to 16 years in Hangzhou, China. BMC Public Health 12, 126.

10. Holick MF (2008) Deficiency of sunlight and vitamin D. BMJ 336, 1318-1319.

11. von Hurst PR, Stonehouse W \& Coad J (2010) Vitamin D status and attitudes towards sun exposure in South Asian women living in Auckland, New Zealand. Public Health Nutr 13, 531-536.

12. Christie FT \& Mason L (2011) Knowledge, attitude and practice regarding vitamin D deficiency among female students in Saudi Arabia: a qualitative exploration. Int J Rheum Dis 14, e22-e29.

13. Bonevski B, Bryant J, Lambert $S$ et al. (2013) The ABC of vitamin D: a qualitative study of the knowledge and attitudes regarding vitamin D deficiency amongst selected population groups. Nutrients $\mathbf{5}, 915-927$.

14. Nelson MC, Story M, Larson NI et al. (2008) Emerging adulthood and college-aged youth: an overlooked age for weight-related behavior change. Obesity (Silver Spring) 16, 2205-2211.

15. Matvienko O, Lewis DS \& Schafer E (2001) A college nutrition science course as an intervention to prevent weight gain in female college freshmen. J Nutr Educ 33, 95-101.

16. Sajwani RA, Shoukat S, Raza R et al. (2009) Knowledge and practice of healthy lifestyle and dietary habits in medical and non-medical students of Karachi, Pakistan. J Pak Med Assoc 59, 650-655.

17. Holick MF (2009) Vitamin D status: measurement, interpretation, and clinical application. Ann Epidemiol 19, 73-78.

18. Nabak AC, Johnson RE, Keuler NS et al. (2014) Can a questionnaire predict vitamin D status in postmenopausal women? Public Health Nutr 17, 739-746.

19. Bolek-Berquist J, Elliott ME, Gangnon RE et al. (2009) Use of a questionnaire to assess vitamin D status in young adults. Public Health Nutr 12, 236-243.

20. Recker RR, Davies KM, Hinders SM et al. (1992) Bone gain in young adult women. JAMA 268, 2403-2408.

21. Hernandez CJ, Beaupre GS \& Carter DR (2003) A theoretical analysis of the relative influences of peak BMD, age-related bone loss and menopause on the development of osteoporosis. Osteoporos Int 14, 843-847.

22. Faurschou A, Beyer DM, Schmedes A et al. (2012) The relation between sunscreen layer thickness and vitamin D production after ultraviolet $\mathrm{B}$ exposure: a randomized clinical trial. Br J Dermatol 167, 391-395.

23. Halpern AC \& Kopp LJ (2005) Awareness, knowledge and attitudes to non-melanoma skin cancer and actinic keratosis among the general public. Int J Dermatol $\mathbf{4 4}$, $107-111$.

24. Langbecker D, Youl P, Kimlin M et al. (2011) Factors associated with recall of media reports about vitamin D and sun protection. Aust N Z J Public Health 35, 159-162.

25. Shi Z, Yuan B, Zhang C et al. (2011) Egg consumption and the risk of diabetes in adults, Jiangsu, China. Nutrition 27, 194-198.

26. Yu A, Kim J, Kwon O et al. (2013) The association between serum 25-hydroxyvitamin D concentration and consumption frequencies of vitamin d food sources in Korean adolescents. Clin Nutr Res 2, 107-114.

27. Rodríguez-Rodríguez E, González-Rodríguez LG, Ortega Anta RM et al. (2013) Consumption of eggs may prevent vitamin D deficiency in schoolchildren. Nutr Hosp 28, 794-801. 